\title{
Adsorption of Tetracycline from Aqueous Solution by Aerobic Granular Sludge-based Biochar: Affecting Factors, Kinetics, Isotherms, and Mechanisms
}

\author{
L. L. Yan, ${ }^{*}$ W. T. Chen, S. Liu, Y. Q. Zheng, \\ J. S. Jiang, and Y. Liu \\ School of Resource and Environment, \\ Northeast Agricultural University, Harbin 150030 China
}

doi: https://doi.org/10.15255/CABEQ.2021.1959

Original scientific paper

Received: April 9, 2021

Accepted: December 2, 2021

\begin{abstract}
In this experiment, the influencing factors of tetracycline (TC) removal by adsorption with the aerobic granular sludge-based biochar (BC) were analyzed. In particular, the specific surface area, pore size distribution, and functional groups of the biochar were studied. In addition, the kinetics, isotherms, and diffusion models of TC removal were examined. The adsorption of TC reached a maximum $\left(16.59 \mathrm{mg} \mathrm{g}^{-1}\right)$ when the biochar carbonization temperature and time were $700{ }^{\circ} \mathrm{C}$ and $2 \mathrm{~h}$, respectively. With increasing initial TC concentration, the adsorption capacity of BC to TC increased gradually. The optimal $\mathrm{pH}$ value of TC adsorption with $\mathrm{BC}$ was 7.0, and a low concentration of salt was found to promote the adsorption of TC. The pseudo second-order kinetic model and Langmuir isotherm model were found to correlate well the adsorption of TC by BC. Both the internal diffusion and liquid film diffusion were the rate-controlling steps of the adsorption process. The alkali-modified BC was found to be the best adsorbent for TC.
\end{abstract}

Keywords:

biochar, tetracycline, aerobic granular sludge, modification

\section{Introduction}

The rapid development of industry and agriculture, along with the improvement of living standard have led to the discharge of a large number of toxic and harmful pollutants via industrial and agricultural wastewater, and municipal sewage plants into the aquatic environment. As a major producer and user of antibiotics, China produces approximately 210,000 tons of antibiotics each year, accounting for more than half of global consumption. Tetracycline (TC) is a natural or semisynthetic antibiotic that can inhibit gram-positive and gram-negative bacteria, chlamydia, mycoplasma, rickettsia, spirochetes, and protozoan parasites. TC has become the most commonly used antibiotic in the prevention and control of human and animal diseases due to its low production cost, good effectiveness, wide spectrum, and high antibacterial activity. ${ }^{1}$ It has been widely used in agriculture and animal husbandry. ${ }^{2}$ TC has good water solubility and a long half-life, is relatively stable under acidic conditions, and easily accumulated and enriched in the environment. Its broad-spectrum antibacterial activity and stable naphthalene structure make TC hard to degrade, and only a small amount of tetracycline is metabolized

"Corresponding author: Tel.: +86 45155190825

E-mail address: yanl198@163.com and absorbed in the body while the rest is directly released into the environment through excrement. Residual TC will not only lead to the production of various drug-resistant bacteria, but will affect the life of aquatic animals; in addition, these residues will enter the human body through drinking water and the food chain, reducing human immunity. ${ }^{3}$

There are many ways to remove antibiotics from wastewater, but the ability of conventional techniques to remove antibiotics is usually limited because these contaminants may be concentrated in repeated water cycles. For this reason, it is necessary to develop a new efficient removal technology for antibiotic-containing wastewater. Although biological methods can effectively remove conventional nutrients, ${ }^{4}$ they cannot effectively remove antibiotics due to inhibition of biological activity. The adsorption method has the advantages of low cost, simple operation, good effectiveness, environmental friendliness, and nontoxicity. ${ }^{5}$ It is one of the most promising technologies, and has been widely used to treat wastewater containing antibiotics. To improve their adsorption capacity, much research has been done on the preparation of adsorbents and influencing factors ${ }^{6,7}$ such as the solution $\mathrm{pH},{ }^{8}$ temperature, concentration. ${ }^{9,10}$ reaction time ${ }^{11}$ and salt concentration. ${ }^{12}$ Further attempts were made to modify adsorbents by means of physical methods, chemical methods, and mineral impregnation meth- 
ods to improve their adsorption capacity. Compared with physical methods, the latter two have the advantages of simple operation, easy process control, and short reaction time. ${ }^{13}$ Currently, commonly used modifiers for biochar adsorbents include $\mathrm{H}_{3} \mathrm{PO}_{4},{ }^{14}$ $\mathrm{NaOH},{ }^{15} \mathrm{KOH},{ }^{16} \mathrm{FeCl}_{3},{ }^{17} \mathrm{Fe}_{3} \mathrm{O}_{4},{ }^{18,19}$ etc.

Sewage treatment plants are not only reservoirs of antibiotics but also sources of antibiotics. In recent years, China's sewage treatment rate has gradually increased, and its environmental water quality has gradually improved. However, sewage treatment plants also produce significant amounts of residual sludge when treating sewage. ${ }^{20}$ According to statistics, China's annual sludge production has continued to grow since 2011, with dry sludge production exceeding 12 million tons in 2017. ${ }^{21} \mathrm{Com}$ pared with sewage treatment, sludge treatment, disposal, and resource utilization are relatively underdeveloped in China. Common sludge treatment methods include incineration, landfilling, and farmland application. ${ }^{22}$ However, because sludge contains many heavy metals, pathogenic microorganisms, parasite eggs, and toxic and harmful substances, ${ }^{23}$ incineration produces a large amount of toxic smoke and ash, and application to farmland and landfills can cause harmful substances to slowly penetrate the soil and groundwater environment, causing secondary environmental pollution. ${ }^{22,24} \mathrm{Ex}$ cess sludge contains a large amount of biomass, organic matter, and rich functional groups, ${ }^{25}$ which can be used to prepare biochar and solve the problem of sludge treatment while realizing resource utilization. Aerobic granular sludge (AGS) has the characteristics of high carbon content, large surface area, good sedimentation, a variety of microorganisms, compact structure, etc. ${ }^{26,27}$ and the internal pores are abundant after its carbonization. The use of biochar for adsorption of heavy metals has broad application prospects, ${ }^{28}$ but little research has been done on the removal of antibiotics, and its antibiotic-removal ability is limited.

From the perspective of environmental friendliness, AGS was used as the substrate to prepare biochar. The purpose of this paper was to optimize the preparation parameters of AGS-based biochar (BC) and to characterize the morphological structure, surface functional groups, pores, and specific surface area of the adsorbent. Factors affecting the adsorption capacity and the adsorption kinetics, isotherms, and diffusion characteristics were evaluated. Furthermore, different modification methods were chosen to improve the adsorption performance of TC. This study is expected to provide some reference value for exploring low-cost, high-efficiency, and nontoxic adsorbents, and provide a reference for the removal of macromolecular organic pollutants such as antibiotics.

\section{Materials and methods}

\section{Materials and reagents}

AGS from the laboratory sequencing batch reactor (SBR) of Northeast Agricultural University was used to prepare the adsorbent in the experiment. In the SBR, AGS particle sizes greater than $2.0 \mathrm{~mm}, 1.2-2 \mathrm{~mm}$, and $0.5-1.2 \mathrm{~mm}$ accounted for $95 \%, 3 \%$, and $2 \%$ of the AGS, respectively. Tetracycline $\left(\mathrm{C}_{22} \mathrm{H}_{24} \mathrm{~N}_{2} \mathrm{O}_{8}\right.$; CAS Number: 60-54-8) was purchased from Shanghai Macklin Biochemical Co. All other drugs used in this study were of analytical purity.

\section{Preparation of adsorbent}

The AGS from the SBR was air-dried naturally. After being crushed through a 100 -mesh sieve, it was placed into a tube furnace. $\mathrm{N}_{2}$ was continuously pumped into the tube furnace to ensure an inert environment, and then the AGS was heated to the designated carbonization temperature at a rate of $5{ }^{\circ} \mathrm{C}$ $\mathrm{min}^{-1}$. The temperature was kept constant for a certain time, and then cooled to room temperature. After grinding and sieving, the sample was washed with $2 \mathrm{~mol} \mathrm{~L}^{-1}$ hydrochloric acid 2-3 times, and then dried at $105{ }^{\circ} \mathrm{C}$ for use.

\section{Characterization of the adsorbent}

The structure and morphology of $\mathrm{BC}$ were characterized by scanning electron microscopy (SU8010, Hitachi, Japan). $\mathrm{N}_{2}$ adsorption-desorption was carried out under liquid nitrogen. The pore size distribution of the adsorbent was calculated by the Dubinin-Radushkevic and Barrett-Joyner-Halenda methods at a relative pressure ratio of $p / p_{0}=0.994$, and the specific surface area of the carbon materials was calculated by Brunauer-Emmett-Teller method (ASAP2020, Micromeritics, USA). Fourier transform infrared spectroscopy (SPECTRUM ONE B, PerkinElmer, USA) was used to analyze chemical bonds and functional groups on the surface of the carbon materials. ${ }^{29}$ The isoelectric point of the adsorbent was measured by the $\mathrm{pH}$ drift method. ${ }^{29}$

\section{Adsorbent preparation and adsorption experiment}

To select the best preparation conditions, BC was prepared at different carbonization temperatures $\left(400{ }^{\circ} \mathrm{C}, 500{ }^{\circ} \mathrm{C}, 600^{\circ} \mathrm{C}\right.$, and $\left.700{ }^{\circ} \mathrm{C}\right)$ and different carbonization times $(1 \mathrm{~h}$ and $2 \mathrm{~h})$ to adsorb TC. Twenty $\mathrm{mL} \mathrm{TC}$ solution $\left(20 \mathrm{mg} \mathrm{L}^{-1}\right)$ was placed into a $50-\mathrm{mL}$ conical flask, $0.015 \mathrm{~g} \mathrm{BC}$ was added, and the flask was sealed with parafilm. The mixture was then shaken at $160 \mathrm{rpm}$ and $25^{\circ} \mathrm{C}$ for $1440 \mathrm{~min}$ in the dark (to minimize photodegradation), centrifuged at $4000 \mathrm{rpm}$ for $10 \mathrm{~min}$, and filtered through 
a $0.22 \mu \mathrm{m}$ filter. The absorbance was then measured at $365 \mathrm{~nm}$ by an ultraviolet spectrophotometer, and the corresponding solution concentration and adsorption amount were calculated according to the standard curve. The TC solution without BC was used for control experiments. All experiments were performed simultaneously in triplicate.

To study the influence of the amount of adsorbent on the adsorption capacity, 0.005, 0.010, 0.015, $0.020,0.025$, and $0.030 \mathrm{~g}(\mathrm{pH}=5.0)$ were added to $20 \mathrm{~mL}\left(20 \mathrm{mg} \mathrm{L}^{-1}\right) \mathrm{TC}$ solution. The mixture was shaken at $160 \mathrm{rpm}$ and $25{ }^{\circ} \mathrm{C}$ for $1440 \mathrm{~min}$ in the dark, and centrifuged at $4000 \mathrm{rpm}$ for $10 \mathrm{~min}$. The supernatant was filtered through a $0.22 \mu \mathrm{m}$ filter, and the $\mathrm{TC}$ concentration was determined.

BC $(0.015 \mathrm{~g})$ was added to $20 \mathrm{~mL}$ TC solution (20 $\mathrm{mg} \mathrm{L}^{-1}$ ), and $0.1 \mathrm{~mol} \mathrm{~L}^{-1} \mathrm{NaOH}$ or $\mathrm{HCl}$ solution was used to adjust the $\mathrm{pH}$ values of the initial TC solutions to $4.0,5.0,6.0,7.0$, and 8.0 to study the influence of $\mathrm{pH}$ on the adsorption capacity. BC $(0.015 \mathrm{~g})$ was added to $20 \mathrm{~mL}$ TC solution $(\mathrm{pH}=$ 5.0), TC concentration $(10,20,30,40,50,60,70$, 80,90 , and $\left.100 \mathrm{mg} \mathrm{L}^{-1}\right)$, different reaction times $(0$, $5,10,20,30,40,50,60,90,120,180,300,480$, 720,1080 , and $1440 \mathrm{~min}$ ), and coexisting salt ions $\left(0,0.2,0.4,0.6,0.8,1\right.$ and $2 \mathrm{~mol} \mathrm{~L}^{-1} \mathrm{NaCl}$ and $\mathrm{CaCl}_{2}$ ) were investigated. The other procedures were the same as above.

Adsorbent modification is an effective method to improve the adsorption capacity for TC. The adsorbents were immersed in $1.0 \mathrm{~mol} \mathrm{~L}^{-1} \mathrm{CH}_{3} \mathrm{COOH}$, $14 \% \mathrm{H}_{3} \mathrm{PO}_{4}, 4.0 \mathrm{~mol} \mathrm{~L}^{-1} \mathrm{NaOH}, 2.0 \mathrm{~mol} \mathrm{~L}^{-1} \mathrm{KOH}$, $2.0 \mathrm{~mol} \mathrm{~L}^{-1} \mathrm{Na}_{2} \mathrm{CO}_{3}$ and $2.0 \mathrm{~mol} \mathrm{~L}^{-1} \mathrm{FeCl}_{3}$ for 1440 min. They were then dried at $105^{\circ} \mathrm{C}$ and placed into a tube furnace. $\mathrm{N}_{2}$ was injected into the furnace for $10 \mathrm{~min}$ to ensure an inert atmosphere, and then the temperature was increased to $700{ }^{\circ} \mathrm{C}$ at a rate of $5{ }^{\circ} \mathrm{C} \mathrm{min}{ }^{-1}$. The temperature was maintained for 120 min, then dropped to room temperature, and $\mathrm{N}_{2}$ flow was continued during the cooling process. After cooling, the samples were ground and screened, cleaned in $2.0 \mathrm{~mol} \mathrm{~L}^{-1}$ hydrochloric acid, dried at $105{ }^{\circ} \mathrm{C}$, and sealed for storage.

In addition, $0.015 \mathrm{~g} \mathrm{BC}$ was added to $20 \mathrm{~mL}$ TC solution $\left(20 \mathrm{mg} \mathrm{L}^{-1}, \mathrm{pH}=5.0\right)$ and shaken at $160 \mathrm{rpm}$ and $25{ }^{\circ} \mathrm{C}$ for $1440 \mathrm{~min}$ in the dark. Samples were collected and measured regularly, and kinetics and diffusion experiments were carried out. Furthermore, $20 \mathrm{~mL}$ TC solution $\left(0-100 \mathrm{mg} \mathrm{L}^{-1}\right)$ was mixed with $0.015 \mathrm{~g} \mathrm{BC}$ and stirred for 1440 min in the dark. Samples were collected and measured for the isotherm experiment.

\section{Formulas and models}

The calculation formula of equilibrium adsorption capacity $q_{e}\left(\mathrm{mg} \mathrm{g}^{-1}\right)$ is as follows: ${ }^{29-31}$

$$
q_{e}=\frac{\left(\gamma_{0}-\gamma_{e}\right) V}{m}
$$

where $\gamma_{0}\left(\mathrm{mg} \mathrm{L}^{-1}\right)$ is the concentration of the initial TC solution, and $\gamma_{\mathrm{e}}\left(\mathrm{mg} \mathrm{L}^{-1}\right)$ is the concentration of the TC solution at equilibrium. $V(\mathrm{~L})$ is the volume of TC solution added. $m(\mathrm{~g})$ is the amount of carbon material added.

Pseudo first-order kinetics, pseudo second-order kinetics, and the Elovich equation were used to describe the kinetics of the TC removal process. ${ }^{11,17,32}$ The Langmuir model, Freundlich model, and Temkin model were further used to describe the TC adsorption isotherm, ${ }^{30-33}$ and internal diffusion and liquid film diffusion models were used to describe the diffusion process of TC..$^{34,35}$

For pseudo first-order kinetics, ${ }^{11}$ the formula is as follows:

$$
\log \left(q_{\mathrm{e}}-q_{t}\right)=\log q_{e}-K_{\mathrm{l}} t
$$

where $q_{e}$ and $q_{t}\left(\mathrm{mg} \mathrm{g}^{-1}\right)$ are the adsorption amounts of TC on carbon materials when the adsorption reaction reaches equilibrium and at a certain time in the adsorption reaction, $K_{1}\left(\mathrm{~min}^{-1}\right)$ is the pseudo first-order adsorption rate constant, and $t$ (min) is time.

For pseudo second-order kinetics, ${ }^{17}$ the calculation formula is as follows:

$$
\frac{\mathrm{t}}{q_{t}}=\frac{1}{K_{2} q_{e}{ }^{2}}+\frac{t}{q_{e}}
$$

where $K_{2}\left(\mathrm{~g}(\mathrm{mg} \mathrm{min})^{-1}\right)$ is the pseudo second-order adsorption rate constant.

For the Elovich equation, ${ }^{33}$ the formula is as follows:

$$
\begin{gathered}
q_{t}=\left(\frac{1}{b}\right) \ln a b+\left(\frac{1}{b}\right) \ln t \\
t_{0}=\frac{1}{a b}
\end{gathered}
$$

where $a$ is the chemisorption rate, and $b$ is a constant related to the surface coverage of the carbon material.

For the Langmuir equation,,$^{33}$ the formula is as follows:

$$
\frac{1}{q_{e}}=\frac{1}{q_{m} K_{L} \gamma_{e}}+\frac{1}{q_{m}}
$$

where $q_{m}\left(\mathrm{mg} \mathrm{g}^{-1}\right)$ is the maximum saturated adsorption capacity related to surface coverage, and $K_{L}\left(\mathrm{~L} \mathrm{mg}^{-1}\right)$ is a constant related to adsorption efficiency. In addition, the separation factor $\left(R_{L}\right)$ based on the Langmuir model is used to evaluate the reaction process, and the equation is as follows:

$$
R_{L}=\frac{1}{1+K_{L} \gamma_{1}}
$$


where $\gamma_{1}\left(\mathrm{mg} \mathrm{L}^{-1}\right)$ is the initial concentration of the TC solution. The results of $R_{L}$ show that the adsorption reaction is favorable $\left(R_{L}>1\right)$, unfavorable $\left(R_{L}<1\right)$, irreversible $\left(R_{L}=0\right)$ or linear $\left(R_{L}=1\right)$.

For the Freundlich equation, ${ }^{30}$ the formula is as follows:

$$
\ln q_{e}=\ln K_{F}+\frac{1}{n} \gamma_{e}
$$

where $K_{F}$ is the adsorption capacity in units of concentration, and $n^{-1}$ is the intensity of adsorption. $n^{-1}$ is the type of isotherm, $\left(n^{-1}<0\right)$, the reaction is irreversible; $\left(0<n^{-1}<1\right)$, spontaneous; $\left(n^{-1}>1\right)$ nonspontaneous.

For the Temkin equation, ${ }^{32}$ the formula is as follows:

$$
q_{e}=a \ln K_{T}+a \ln \gamma_{e}
$$

where $K_{T}\left(\mathrm{~L} \mathrm{mg}^{-1}\right)$ is the equilibrium bond constant related to the maximum energy of the bond.

For intraparticle diffusion, ${ }^{34,35}$ the formula is as follows:

$$
q_{t}=K_{t} \sqrt{t}+c_{t}
$$

where $K_{t}\left(\mathrm{mg} \mathrm{g}^{-1} \min ^{1 / 2}\right)$ is the intraparticle diffusion rate constant, and $c\left(\mathrm{mg} \mathrm{g}^{-1}\right)$ is a constant involving the thickness and boundary.

For liquid film diffusion, ${ }^{15}$ the formula is as follows:

$$
\ln \left(1-\frac{q_{t}}{q_{e}}\right)=-K_{f d} t
$$

where $K_{f d}\left(\mathrm{~min}^{-1}\right)$ is the liquid film diffusion coefficient.

\section{Results and discussion}

\section{Optimization of preparation conditions and selection of sludge particle size}

The adsorption results of TC by BC prepared at different carbonization temperatures and times showed that the $\mathrm{BC}$ prepared at $700{ }^{\circ} \mathrm{C}$ for $2 \mathrm{~h}$ had the best adsorption capacity for TC (Fig. 1). Pyrolysis temperature affected the adsorbent pore structure and adsorption capacity for organic pollutants. ${ }^{36}$ The organic matter in pores burned at high temperature. Meanwhile, the moisture and volatile components were gradually released from the $\mathrm{BC}$ in the form of gas during the dehydration and pyrolysis process, which improved the pore structure, forming a large specific surface area and many pores, helping to improve the adsorption performance. However, too high temperature causes a violent vaporization reaction, leading to the destruction of micropores and reducing the surface area. ${ }^{37}$ In addition, long-term heat treatment causes the pores of

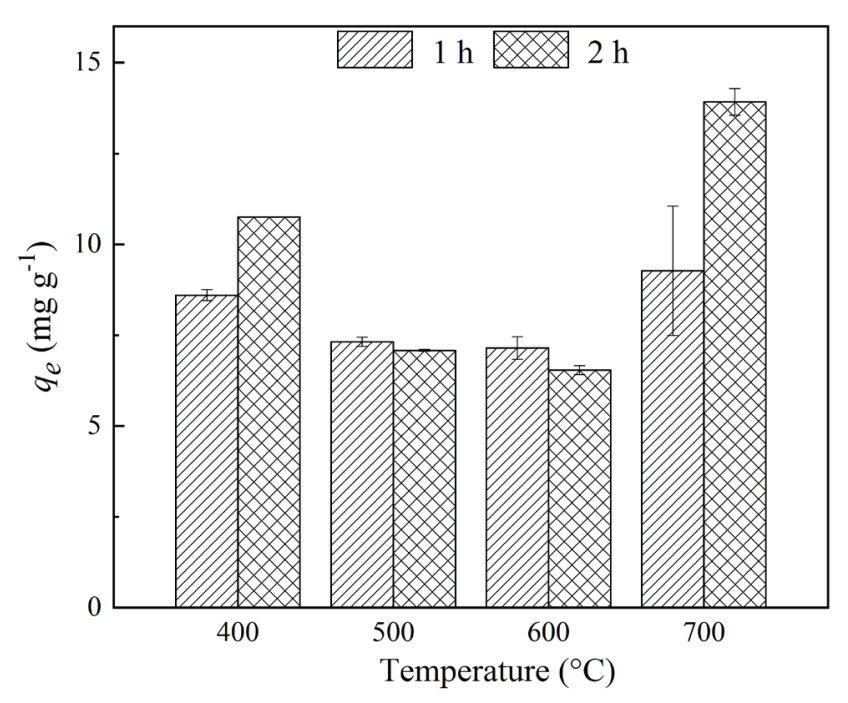

Fig. 1 - Effect of different carbonization temperatures and times on TC adsorption

$\mathrm{BC}$ to collapse or be destroyed, while too short pyrolysis time leads to insufficient reaction of components in the sludge, which is not conducive to the formation of pores.

\section{Characterization of adsorbent}

At low magnification, the surface of $\mathrm{BC}$ was rough and had a wrinkled structure (Fig. 2a). At high magnification, many pores and cavities were observed on the surface of BC. The carbon frame structure was clear and obvious, the porous structure was neatly arranged, and the pore distribution was concentrated and uniform. This was because the sludge contained a large number of organic substances, which gasified and volatilized under high temperature conditions, resulting in a large number of pores.

The $\mathrm{N}_{2}$ adsorption-desorption isotherm of $\mathrm{BC}$ deviated from the Y-axis at the low-pressure end $(0.0-0.1)$, indicating that $\mathrm{BC}$ had a strong adsorption capacity for nitrogen and more micropores (Fig. 2b). Due to the strong adsorption potential in the micropores, the adsorption curve was type I at the beginning, and the adsorption reached saturation rapidly, which indicated a typical monolayer adsorption and a characteristic micropore filling. ${ }^{38}$ The medium pressure end $(0.3-0.8)$ was mostly the condensation accumulation of nitrogen in the material pores, including the pores generated by the accumulation of sample particles, and the Barrett-Joyner-Halenda (BJH) method was based on the pore size data obtained in this section. The isotherm of the high-pressure section (0.9-1.0) rose sharply, which indicated that there were macropores (pore size greater than $50 \mathrm{~nm}$ ) and uneven particles in $\mathrm{BC} .{ }^{25} \mathrm{In}$ the process of adsorption and desorption, the curves 
(a)
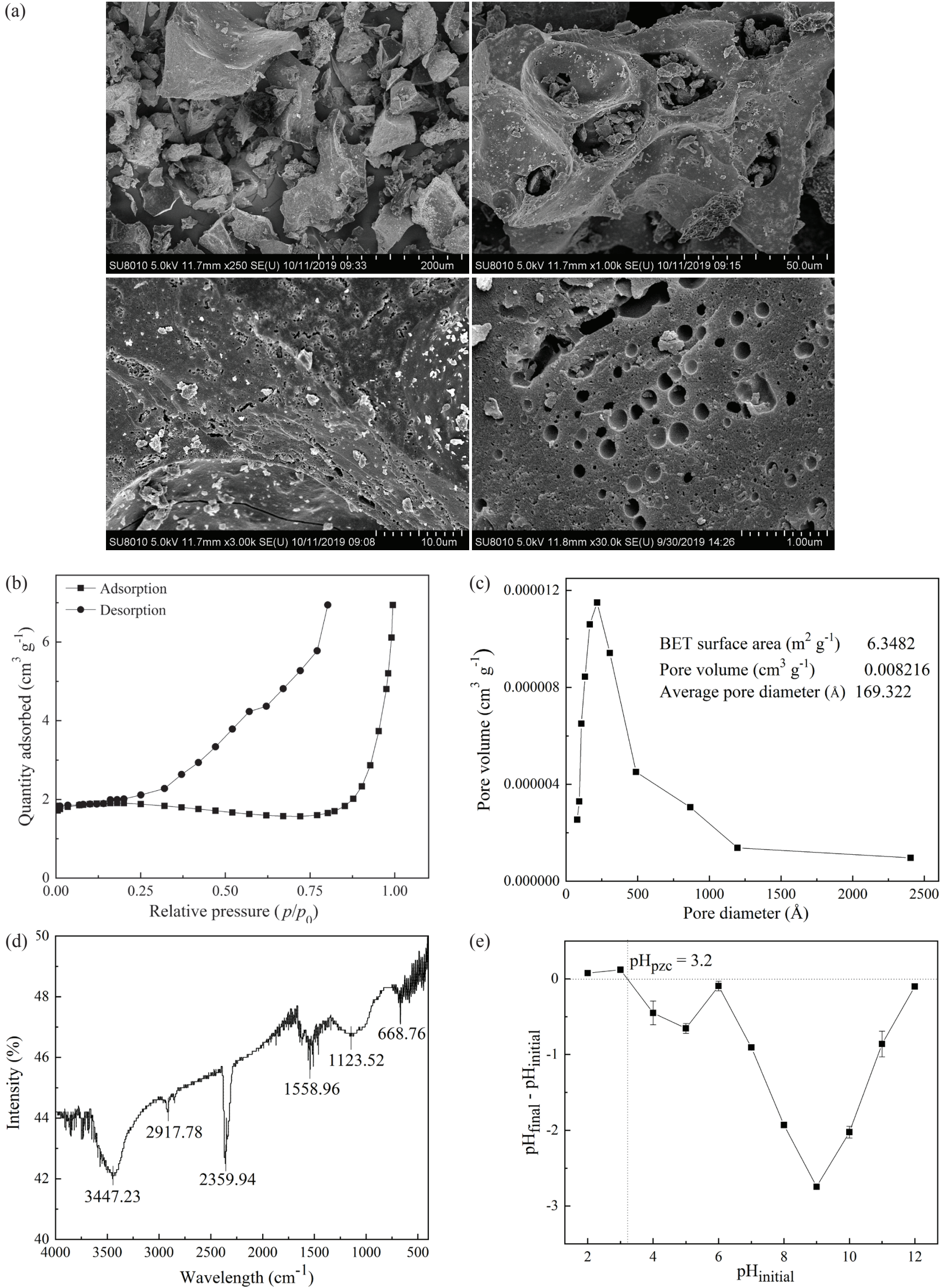

(e)

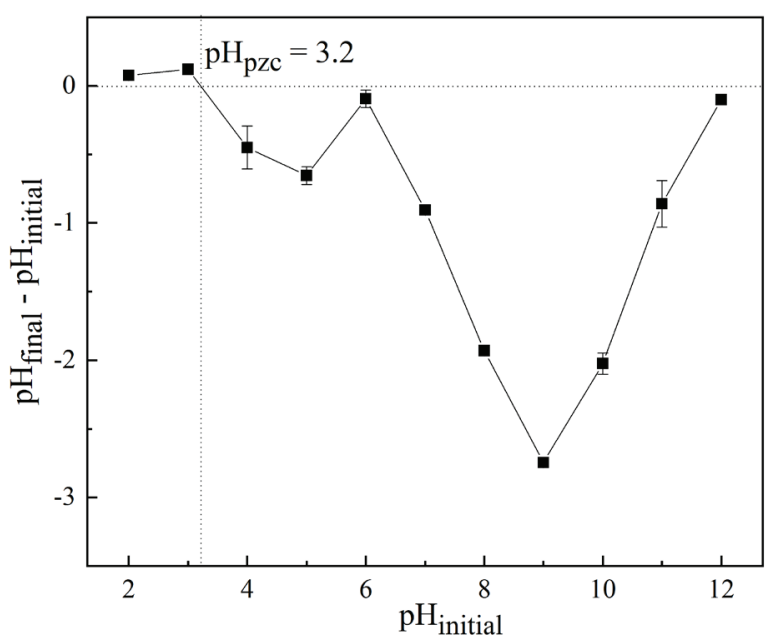

Fig. 2 - (a) Scanning electron microscopy of BC; (b) Nitrogen adsorption-desorption curve of BC; (c) Pore size distributions of BC; (d) FTIR spectra of $B C\left(700^{\circ} \mathrm{C}\right)$; (e) $\mathrm{pH}$ prc of $B C$ 
did not overlap, but a hysteresis loop appeared, indicating that capillary agglutination occurred during $\mathrm{N}_{2}$ adsorption and desorption of the $\mathrm{BC}$.

It has previously been reported that pollutants cannot be adsorbed effectively due to the size exclusion effect when the average pore size of biochar is less than 1.7 times the second widest dimension of the molecule. ${ }^{39}$ Similarly, Liou reported that the pore structure of carbon materials affected the adsorption process of organic matter, and a large number of pores were necessary for the rapid transfer of adsorbate to biochar. ${ }^{40}$ In addition, Risvera-Utrilla et al. reported that biochar needed a sufficiently large pore size so that pollutant molecules could easily enter the adsorption sites in the pores. ${ }^{41}$ The average pore size of $\mathrm{BC}$ in this experiment was $169.322 \AA$, which was much larger than the size of the TC molecule (12.9 $\AA$ in length when fully protonated) (Fig. 2c). It is speculated that BC can efficiently adsorb TC, ${ }^{39-41}$ and pore filling may be one of the mechanisms of adsorption of TC by biochar. ${ }^{42}$

The results of infrared spectroscopy showed that the surface of $\mathrm{BC}$ was rich in oxygen-containing polar functional groups (Fig. 2d). The peak at $3447 \mathrm{~cm}^{-1}$ corresponds to the stretching vibration of the intermolecular hydrogen bond association of alcohol and phenol hydroxyl $(-\mathrm{OH})$. The peak at 1123 $\mathrm{cm}^{-1}$ represents a characteristic peak of benzene rings or aromatic groups $(\mathrm{C}=\mathrm{C}),{ }^{43}$ indicating that $\mathrm{BC}$ contained benzene rings. At $2917 \mathrm{~cm}^{-1}$, aliphatic or cycloaliphatic $-\mathrm{CH}_{2}$ and $-\mathrm{CH}_{3}$ stretching vibrations were observed. ${ }^{42}$ At the characteristic absorption peaks at $668 \mathrm{~cm}^{-1}$ and $1558 \mathrm{~cm}^{-1}$, ether bond $(\mathrm{C}-\mathrm{O}-\mathrm{C})$ and carbonyl group $(\mathrm{C}=\mathrm{O})$ bending vibrations representing saturated six-membered dioxane ethers were observed. These oxygen-containing functional groups can act as $\pi$ electron acceptors in $\pi-\pi$ electron donor-acceptor interactions ${ }^{45}$ and then form $\pi-\pi$ conjugates with the aromatic ring structure in TC. In addition, these hydrophilic oxygen-containing functional groups can also establish a strong $\mathrm{H}$ bond with the phenolic groups of $\mathrm{TC},{ }^{36}$ which can easily attract water molecules to form three-dimensional water groups and reduce the hydrophobic effect, ${ }^{46}$ and this is also beneficial to the entire adsorption process. The characteristic peak at $2359 \mathrm{~cm}^{-1}$ may have been caused by $\mathrm{CO}_{2}$ in the air when the sample was tested. During the entire reaction process, no carboxyl group $(-\mathrm{COOH})$ was found. This may be because at a higher carbonization temperature $\left(700{ }^{\circ} \mathrm{C}\right)$, the aromaticity of $\mathrm{BC}$ increased, and oxygen-containing functional groups on the surface, such as carboxyl groups, were ignited, resulting in the loss of carboxyl groups. ${ }^{47}$

The isoelectric point results showed that the isoelectric point of BC was approximately 3.2 (Fig.
$2 \mathrm{e})$. When the $\mathrm{pH}$ of the solution $<\mathrm{pH}_{\mathrm{pzc}}$, the surface of the adsorbent was positively charged; when the $\mathrm{pH}$ of the solution> $\mathrm{pH}_{\mathrm{pzc}}$, the surface of the adsorbent was negatively charged. ${ }^{25}$

\section{Factors affecting the adsorption of TC}

The adsorption capacity of BC on TC increased with increasing adsorbent dose (Fig. 3a). It first increased, then tended to stabilize, essentially reaching an equilibrium state at $0.015 \mathrm{~g}$. In the initial stage, the adsorbent dose was small, and the adsorption sites were limited, so the amount of TC adsorbed was also limited. With increasing adsorbent dose, more exposed adsorption sites were provided for the adsorption of TC; $;^{10}$ thus, more TC could be absorbed. However, when the adsorption reached the saturation state, the continuously increasing adsorbent could not be fully utilized, resulting in vacant sites. In contrast, the density of the adsorption sites was too high, which covered each other and caused blockage, leading to a slow increase in the amount of TC removed by the adsorbent. Taking into account the cost of raw materials and comprehensive analysis of the removal results, $0.015 \mathrm{~g}$ was selected as the optimal addition amount of BC in the experiment.

TC is a hydrophilic amphiphilic molecule containing weakly acidic enoic and phenolic hydroxyl groups and basic dimethylamino groups. The solubilities of TC at $15.15,20.15$, and $30.15^{\circ} \mathrm{C}$ were 201 , 311 , and $430 \mathrm{mg} \mathrm{L}^{-1}$, respectively, ${ }^{9}$ and $\mathrm{pH}$ had a great influence on the state in which it was present. ${ }^{8}$

The adsorption capacity first increased and then decreased (Fig. 3b), and reached its maximum $\left(17.19 \mathrm{mg} \mathrm{g}^{-1}\right)$ at $\mathrm{pH}=7.0$. At the same time, it can be seen that the adsorption capacities of TC were similar in the $\mathrm{pH}$ range of 5.0-7.0. Different adsorbent materials had different optimal $\mathrm{pH}$ values. For example, the optimal $\mathrm{pH}$ value of pig manure and straw biochar modified by $\mathrm{H}_{3} \mathrm{PO}_{4}$ was $9.0 .^{48}$ In the process of increasing the $\mathrm{pH}$ value from 4.0 to 7.0 , TC mainly existed in the form of $\mathrm{TC}_{2}{ }^{0}$, and the surface of the adsorbent was negatively charged. At this time, the electrostatic repulsion was small, ${ }^{16}$ so the adsorption capacity was high. When the $\mathrm{pH}$ value further increased above 7.7, TC mainly existed in the form of TC $\mathrm{H}^{-}$and $\mathrm{TC}_{,}^{2,3,5-8}$ and the electrostatic repulsion between the anion and the negatively charged adsorbent increased, so the adsorption capacity decreased. In addition, when the solution was more alkaline, the active sites on the surface of the biochar may be passivated, thereby reducing their ability to remove TC, while part of the TC was still adsorbed at this time. It is inferred that pore filling, $\pi-\pi$ interactions, and hydrogen bonding are also involved in the TC adsorption process. ${ }^{31}$ 

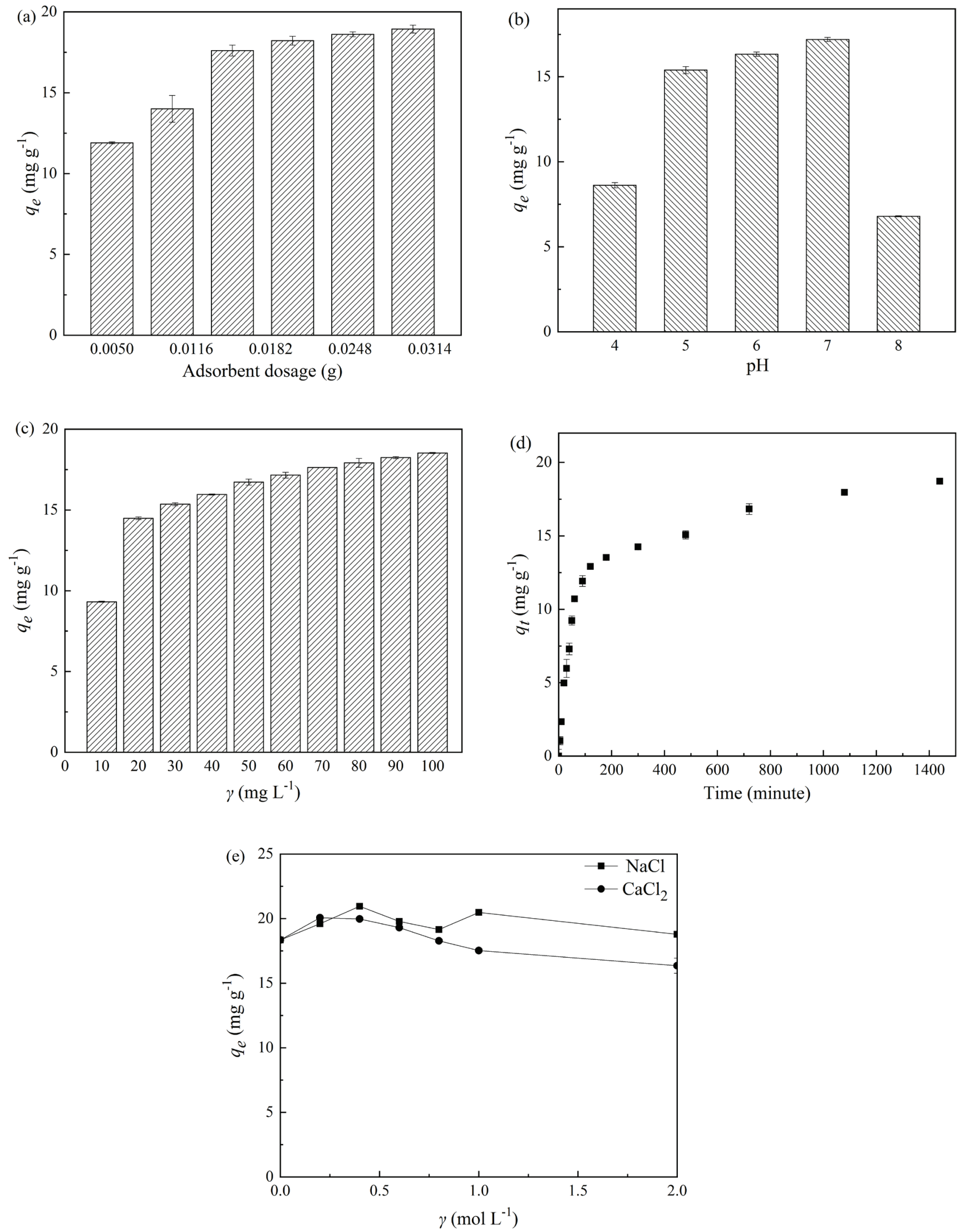

Fig. 3 - (a) Effect of adsorbent dosage on TC removal efficiency; (b) Effect of $p H$ value on TC removal efficiency; (c) Effect of initial TC concentration on TC removal efficiency; (d) Effect of contact time on TC removal efficiency; (e) Effect of salt concentration on TC removal efficiency 
With the increase in the initial concentration of TC solution, the TC adsorption capacity of BC gradually increased (Fig. 3c). In the initial stage, the TC concentration was higher. As the driving force of the concentration difference increased, ${ }^{9}$ more TC molecules moved from aqueous solution to adsorption sites on the surface of the $\mathrm{BC}$; at this time, $\mathrm{BC}$ had a higher TC adsorption capacity. When the concentration of TC solution gradually increased from $20 \mathrm{mg} \mathrm{L}^{-1}$, the probability of adsorbed molecules decreased, and the adsorption rate became slower because the adsorption sites were limited and most of them were bound. ${ }^{10}$

The adsorption capacity of TC by BC showed a trend of rapid increase and achieved stability (the adsorption capacity only increased by $0.76 \mathrm{mg} \mathrm{g}^{-1}$ from 1080 to $1440 \mathrm{~min}$ ) with time (Fig. 3d). The adsorption process was divided into fast adsorption, slow adsorption, and equilibrium stages. ${ }^{11}$ The early stage of the TC adsorption reaction was a rapid adsorption process. Approximately $90 \%$ of the adsorption capacity appeared in the initial stage. Initially, there are abundant active sites on the surface of $\mathrm{BC}$, and the initial concentration of TC is relatively high. A higher concentration difference accelerates the reaction and produces a greater driving force for mass transfer, and the outer surface of the adsorbent and the microporous structure of the adsorbent work synergistically so that TC quickly occupies the adsorption sites on the surface of the BC, resulting in a rapid increase in adsorption capacity. As time went by, the active sites gradually reached saturation, the number of active sites with adsorption capacity decreased, the concentration difference of TC in the solid-liquid phase decreased continuously, so the adsorption rate slowed down until it reached equilibrium.

The low-concentration salt ions promoted the adsorption of TC by BC. When $0.05 \mathrm{~mol} \mathrm{~L}^{-1} \mathrm{NaCl}$ and $0.025 \mathrm{~mol} \mathrm{~L}^{-1} \mathrm{CaCl}_{2}$ were added, the adsorption capacity reached 20.96 and $20.07 \mathrm{mg} \mathrm{g}^{-1}$, respectively, with increases of 2.61 and $1.72 \mathrm{mg} \mathrm{g}^{-1}$, which had a significant promoting effect on the adsorption process (Fig. 3e). The high concentration of salt ions competed with TC for adsorption sites, causing electrostatic screening, and thereby inhibiting the adsorption capacity of TC. At the same time, when the salt ion concentration was so high that it occupied the active sites, the probability of contact be- tween the pores on the surface of $\mathrm{BC}$ and TC molecules was reduced, thereby inhibiting the adsorption of TC. In addition, TC can form complexes with cations in high-concentration salt solutions, ${ }^{12}$ which also reduces the removal efficiency of TC. Compared with $\mathrm{NaCl}, \mathrm{CaCl}_{2}$ had a greater impact on the adsorption of TC, which may be because $\mathrm{Ca}^{2+}$ easily chelated with the phenolic $\beta$-diketone part of TC, reducing the probability of binding of functional groups on the surface of the $\mathrm{BC}$ with TC. ${ }^{49}$ At the same time, $\mathrm{Ca}^{2+}$ had a greater electronic screening effect and hydration radius, and more easily occupied adsorption sites than $\mathrm{Na}^{+},{ }^{43}$ thereby reducing the adsorption effect.

\section{Analysis of adsorption kinetics, isotherms, and diffusion models}

To clarify the adsorption mechanism of TC to $\mathrm{BC}$, pseudo first-order, pseudo second-order and Elovich models were used to analyze the kinetic characteristics of the adsorption of TC by BC (Fig. 4).

Compared with the pseudo first-order model, the pseudo second-order model $\left(R^{2}=0.996\right)$ better fitted the kinetic characteristics of TC (Fig. 4 and Table 1), which was consistent with literature research. ${ }^{50}$ The adsorption process of $\mathrm{TC}$ to $\mathrm{BC}$ was mainly dominated by chemical adsorption, including electron sharing, electron transfer, and $\pi-\pi$ interactions between the adsorbent and pollutant. ${ }^{51}$ The Elovich model also fitted the experimental results well, indicating that the surface of BC was heterogeneous in energy, and that chemical adsorption occurred on the surface. ${ }^{9}$ Due to this chemical interaction, the combination of $\mathrm{BC}$ and $\mathrm{TC}$ had stable physical and chemical properties, and caused no secondary pollution. According to the calculation results of the pseudo second-order kinetic model, the maximum adsorption capacity of TC on BC was $19.17 \mathrm{mg} \mathrm{g}^{-1}$, which was close to the adsorption capacity measured in experiments $\left(16.59 \mathrm{mg} \mathrm{g}^{-1}\right)$. The adsorption process was very fast because the adsorption rate constant was always less than 1 .

The adsorption isotherm refers to the relationship between pollutant concentration $\left(\gamma_{e}\right)$ and adsorption quantity $\left(q_{\mathrm{e}}\right)$ in aqueous solution when adsorption reaches equilibrium at a certain temperature. The calculation results and related parameters of different temperature models are shown in Fig. 5 and in Table 2.

Table 1 - Kinetic parameters of TC adsorption by $B C$

\begin{tabular}{ccccc}
\hline Dynamic model & \multicolumn{3}{c}{ Kinetic parameter } \\
\hline Pseudo first-order & $R^{2}=0.897$ & $q=12.23 \mathrm{mg} \mathrm{g}^{-1}$ & $K_{1}=1.17 \cdot 10^{-3} \mathrm{~min}^{-1}$ \\
Pseudo second-order & $R^{2}=0.996$ & $q=19.17 \mathrm{mg} \mathrm{g}^{-1}$ & $K_{2}=7.25 \cdot 10^{-4} \mathrm{~g}\left(\mathrm{mg} \cdot \mathrm{min}^{-1}\right.$ \\
Elovich & $R^{2}=0.969$ & $a=0.93$ & $b=0.31$ & $t_{0}=3.45 \mathrm{~min}$ \\
\hline
\end{tabular}



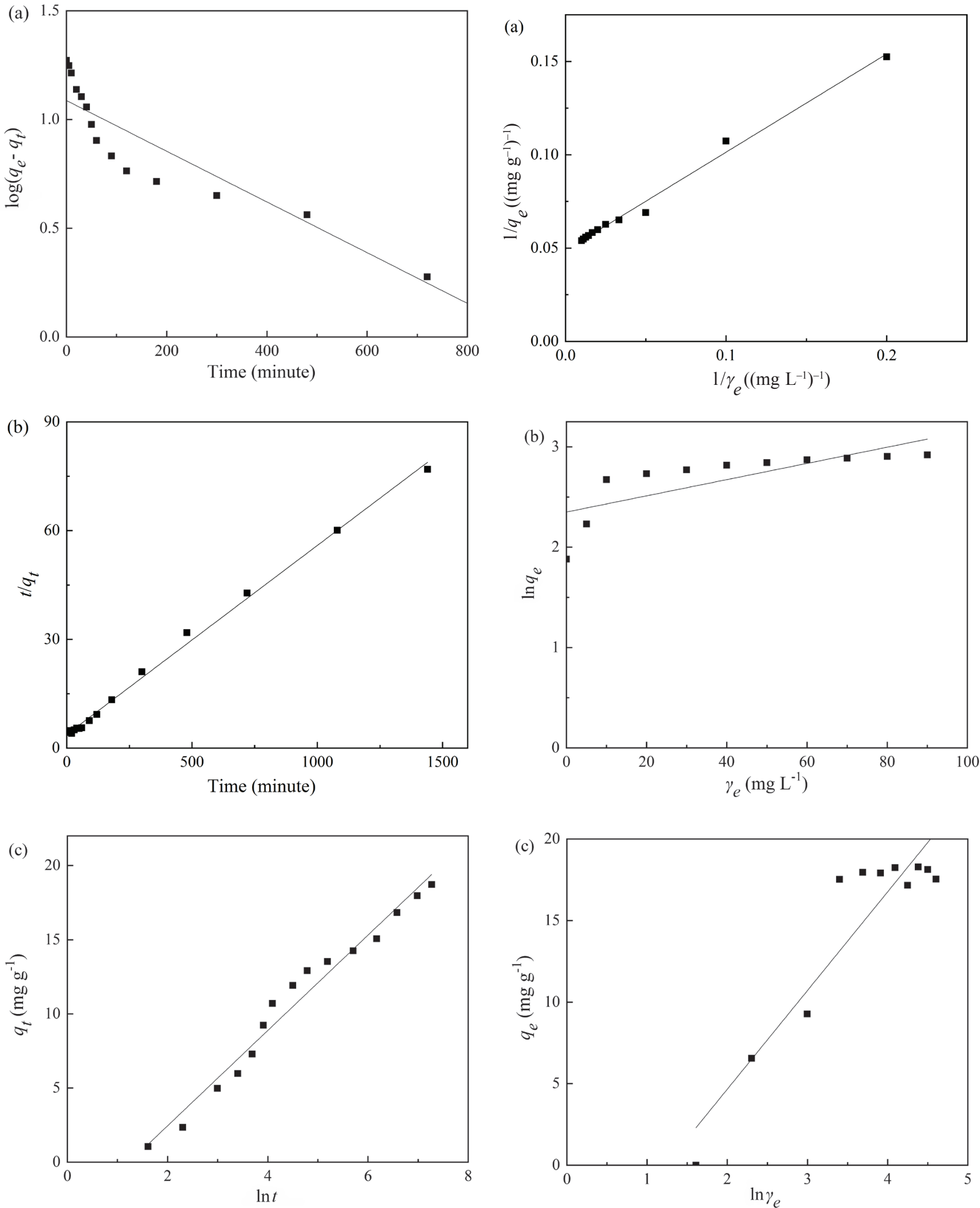

Fig. 4 - Adsorption kinetic models of TC adsorption by BC: (a) pseudo first-order model; (b) pseudo second-order model; (c) Elovich model

Fig. 5 - Adsorption isotherm models of TC adsorption by BC: (a) Langmuir; (b) Freundlich; (c) Temkin 
Compared with the Freundlich model, the Langmuir model had a higher correlation coefficient $\left(R^{2}=0.990\right)$ and therefore fitted the experimental data better (Fig. 5 and Table 2), which was similar to the results of other literature studies, ${ }^{52}$ indicating that the TC monolayer was uniformly adsorbed on the adsorbent, and various adsorption sites on the adsorbent surface were equal in energy to TC. Furthermore, the maximum adsorption capacity calculated according to the Langmuir model was $20.49 \mathrm{mg} \mathrm{g}^{-1}$, and the calculated separation factors $R_{L}$ and $n^{-1}$ were 0.097 and 0.008 , respectively. The adsorption process of TC on $\mathrm{BC}$ was beneficial under operating conditions $\left(R_{L}<1,0<n^{-1}<1\right) .{ }^{32}$ The Temkin model also fitted the experimental data well, indicating that intermolecular forces were involved in the adsorption of TC by BC. ${ }^{9}$ To understand the adsorption reaction mechanism and rate controlling steps in depth, intraparticle diffusion and liquid film diffusion models were used to study the adsorption process. The diffusion results and related parameters of TC adsorption by BC are shown in Fig. 6 and Table 3.

The adsorption process went through multiple stages of external diffusion, adsorption, and equilibrium. Usually, the first stage was related to the external diffusion resistance, while the second and third stages were related to the internal diffusion of particles. The curve fitted by internal diffusion model was multilinear (three linear parts) (Fig. 6a). The first stage was the external fast adsorption stage, and the adsorption amount was almost proportional to the reaction time (Fig. 6a). $K_{t}$ was significantly higher than that of the other two stages (Table 3). At this stage, TC molecules migrated from the liquid phase to the outer surface of the BC through the hydrodynamic boundary layer across the water film. ${ }^{13}$ The two were constantly in contact and collided, reflecting the diffusion rate of particles around the water film. In the second stage, the adsorption capacity increased slowly. At this stage, TC molecules were adsorbed from the outer surface of $\mathrm{BC}$ to the active sites of the pores, reflecting the internal diffusion rate of particles. In the third stage,
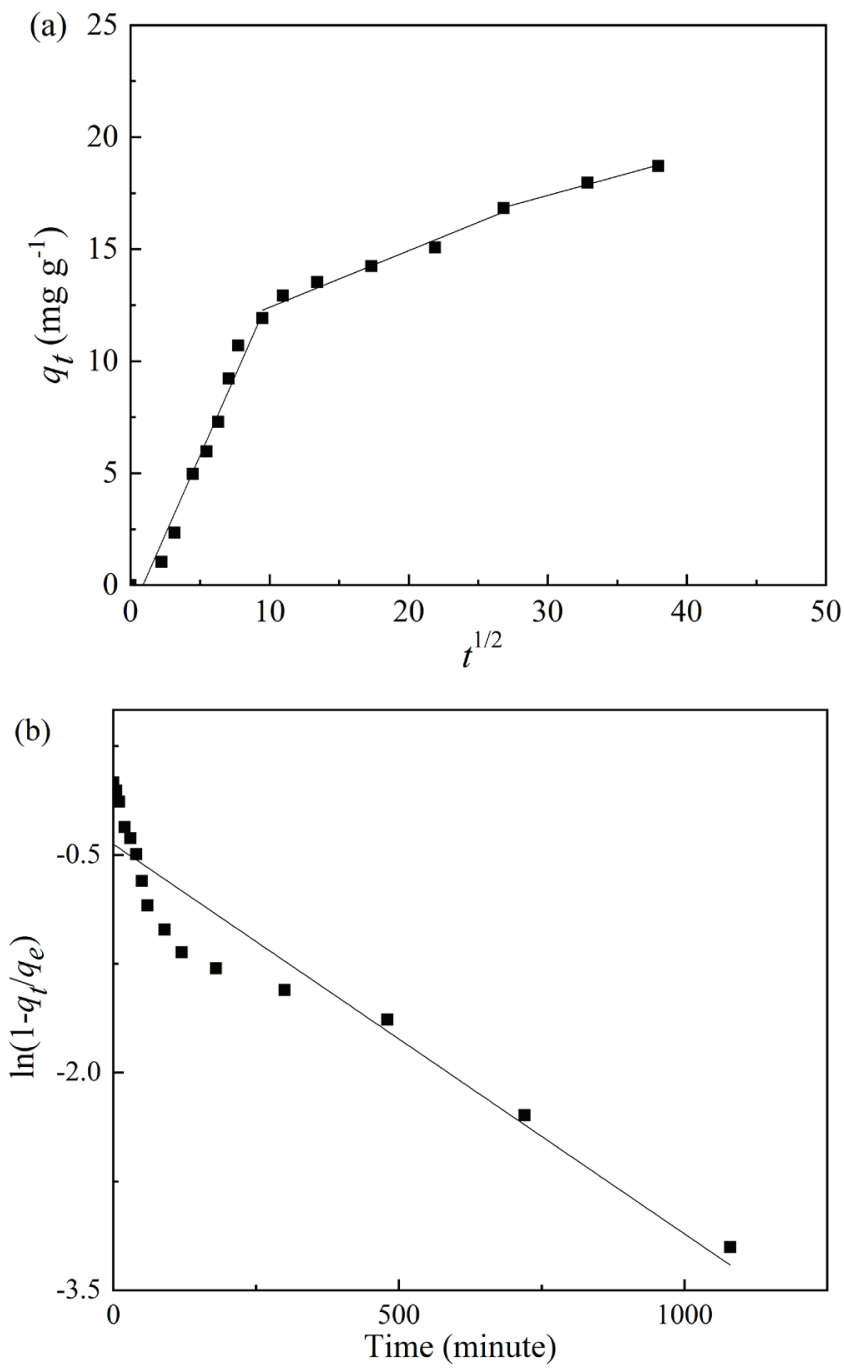

Fig. 6 - Diffusion models of TC adsorption by BC: (a) intraparticle diffusion; (b) liquid film diffusion

Table 2 -Isotherm parameters of TC adsorption by BC

\begin{tabular}{cllll}
\hline Isotherm model & \multicolumn{3}{c}{ Isotherm parameters } \\
\hline Langmuir & $R^{2}=0.990$ & $q_{m}=20.49 \mathrm{mg} \mathrm{g}^{-1}$ & $K_{L}=9.28 \cdot 10^{-2} \mathrm{~L} \mathrm{mg}^{-1}$ \\
Freundlich & $R^{2}=0.539$ & $n=123.76$ & $K_{F}=10.49$ \\
Temkin & $R^{2}=0.851$ & $a=6.05$ & $K_{T}=0.29 \mathrm{~L} \mathrm{mg}^{-1}$ \\
\hline
\end{tabular}

Table 3 - Diffusion parameters of TC adsorption by BC

\begin{tabular}{c|ccc}
\hline Diffusion model & \multicolumn{3}{c}{ Diffusion parameters } \\
\hline Diffusion & $R^{2}=0.962$ & $c_{t}=-1.26 \mathrm{mg} \mathrm{g}^{-1}$ & $K_{t}=1.41 \mathrm{mg} \mathrm{g}^{-1} \mathrm{~min}^{1 / 2}$ \\
& $R^{2}=0.965$ & $c_{t}=9.87 \mathrm{mg} \mathrm{g}^{-1}$ & $K_{t}=0.25 \mathrm{mg} \mathrm{g}^{-1} \mathrm{~min}^{1 / 2}$ \\
& $R^{2}=0.992$ & $c_{t}=12.29 \mathrm{mg} \mathrm{g}^{-1}$ & $K_{t}=0.17 \mathrm{mg} \mathrm{g}^{-1} \mathrm{~min}^{1 / 2}$ \\
Liquid film diffusion & $R^{2}=0.897$ & $K_{f d}=2.69 \cdot 10^{-3} \mathrm{~min}^{-1}$ \\
\hline
\end{tabular}


the adsorption of $\mathrm{TC}$ by $\mathrm{BC}$ tended to balance, which may have been due to the decrease in free adsorption sites of $\mathrm{BC}$ and the increase in electrostatic repulsion between TC molecules adsorbed on the surface of BC and TC molecules in solution. ${ }^{49}$ In this experiment, the intercepts of both the internal diffusion model (Fig. 6a) and the liquid film diffusion (Fig. 6b) fitting curve did not pass through the origin and were close to 0 , indicating that liquid film diffusion also controlled the reaction rate.

\section{Adsorption mechanism}

Understanding the mechanism of pollutant adsorption is critical to the design of carbon-based adsorbent materials. Previous studies have shown that electrostatic interactions, $\pi-\pi$ interactions, hydrogen bonding, and pore filling play key roles in the adsorption of TC by biochar. ${ }^{53}$ To clarify the adsorption mechanism of $\mathrm{TC}$ by $\mathrm{BC}$, this study observed the surface structure of $\mathrm{BC}$, analyzed the functional groups on the surface of the adsorbent material, and comprehensively analyzed the effect of kinetics, isotherms, diffusion characteristics, and solution $\mathrm{pH}$ on the adsorption of TC. It was concluded that the TC molecules were first transferred to the surface of the carbon material through liquid film diffusion and were filled at the active sites on the surface of the carbon material through the pores to form monolayer TC molecules. As the monolayer adsorption approached saturation, the adsorbent began to adsorb TC through chemical adsorption, and there were $\pi-\pi$ interactions and hydrogen bonds in this process. ${ }^{32}$ In addition, the adsorption process was affected by static electricity.

\section{Comparison of adsorption performance between BC and other adsorption materials}

The choice of adsorbent is the core of the entire adsorption technology. Finding a cheap and efficient adsorbent is the key to adsorbing and removing pollutants. For this reason, agricultural waste (straw, livestock and poultry manure, bacterial residue), industrial waste, activated sludge, and other materials have been used to prepare adsorbents, and the synthesis of new adsorbent materials has been frequently attempted to efficiently remove pollutants. As a very promising treatment process, AGS shows excellent removal efficiency and strong anti-shock capacity in removing pollutants. ${ }^{58}$ However, this process will inevitably produce a large amount of excess sludge. The disposal and resource utilization of sludge is one of the urgent problems to be solved in China's sewage treatment plants. ${ }^{23}$ Table 4 shows a comparison of TC adsorption by $\mathrm{BC}$ used in this study and other original carbon materials.
Table 4-Comparison of TC adsorption performance between $B C$ and other carbon materials

\begin{tabular}{|c|c|c|c|}
\hline Raw materials & $\begin{array}{c}\text { Surface } \\
\text { area } \\
\left(\mathrm{m}^{2} \mathrm{~g}^{-1}\right)\end{array}$ & $\begin{array}{c}\text { Adsorption } \\
\text { quantity } \\
\left(\mathrm{mg} \mathrm{g}^{-1}\right)\end{array}$ & Reference \\
\hline Reed & 965.31 & 173.61 & 54 \\
\hline Rice straw & & 13.27 & 55 \\
\hline Red soil & & 12 & 56 \\
\hline Graphene oxide & & 314 & 33 \\
\hline Carbon nanotubes & 207 & 192.7 & 57 \\
\hline AA waste & 46.56 & 11.9 & 10 \\
\hline Waste coffee & & 39.22 & 12 \\
\hline Aerobic granular sludge & 6.35 & 20.96 & In this study \\
\hline $\begin{array}{l}\text { Aerobic granular sludge } \\
\left(\mathrm{Na}_{2} \mathrm{CO}_{3} \text { modified }\right)\end{array}$ & & 19.72 & In this study \\
\hline $\begin{array}{l}\text { Aerobic granular sludge } \\
\left(\mathrm{CH}_{3} \mathrm{COOH} \text { modified }\right)\end{array}$ & & 31.97 & In this study \\
\hline $\begin{array}{l}\text { Aerobic granular sludge } \\
\qquad\left(\mathrm{H}_{3} \mathrm{PO}_{4} \text { modified }\right)\end{array}$ & & 23.90 & In this study \\
\hline $\begin{array}{l}\text { Aerobic granular sludge } \\
\quad\left(\mathrm{FeCl}_{3} \text { modified }\right)\end{array}$ & & 28.93 & In this study \\
\hline $\begin{array}{l}\text { Aerobic granular sludge } \\
(\mathrm{NaOH} \text { modified })\end{array}$ & & 44.88 & In this study \\
\hline $\begin{array}{l}\text { Aerobic granular sludge } \\
\text { (KOH modified) }\end{array}$ & & 45.70 & In this study \\
\hline
\end{tabular}

It may be seen from Table 4 that the $\mathrm{BC}$ derived from AGS in this study had similar TC adsorption performance to other carbon materials. The source of AGS was more widely available than waste coffee and reed. The biochar prepared by AGS had a larger adsorption capacity than rice straw. Compared with carbon nanotubes and graphene oxide, AGS caused no potential pollution to the environment. Meanwhile, the preparation process of $\mathrm{BC}$ in this study was simpler, and $\mathrm{BC}$ with good TC adsorption capacity could be prepared without complex pretreatment, thus reducing the manufacturing cost. It not only realized the recycling of residual sludge but also provided a new direction for the removal of organic pollutants such as antibiotics from wastewater. Thus, BC of this study has a good application prospect in the field of water treatment.

\section{Modification of different substances}

The results of modified $\mathrm{BC}$ adsorption experiments showed that the adsorption capacity of TC by $\mathrm{BC}$ treated with $\mathrm{Na}_{2} \mathrm{CO}_{3}$ basically had not increased $\left(19.72 \mathrm{mg} \mathrm{g}^{-1}\right.$ ) (Fig. 7c). The adsorption capacity of $\mathrm{BC}$ treated with $\mathrm{CH}_{3} \mathrm{COOH}, \mathrm{H}_{3} \mathrm{PO}_{4}$, and $\mathrm{FeCl}_{3}$ was 
limited (31.97, 23.90, and $\left.28.93 \mathrm{mg} \mathrm{g}^{-1}\right)$ (Fig. 7a, 7c), while $\mathrm{NaOH}$ and $\mathrm{KOH}$ greatly improved the TC adsorption capacity of BC (44.88 and $\left.45.70 \mathrm{mg} \mathrm{g}^{-1}\right)$ (Fig. 7b). This was because the vapor formed by alkali treatment at high temperature had an etching effect,$^{59}$ which increased the porosity of $\mathrm{BC}^{13}$ and provided more adsorption sites and spaces. ${ }^{60}$ Other
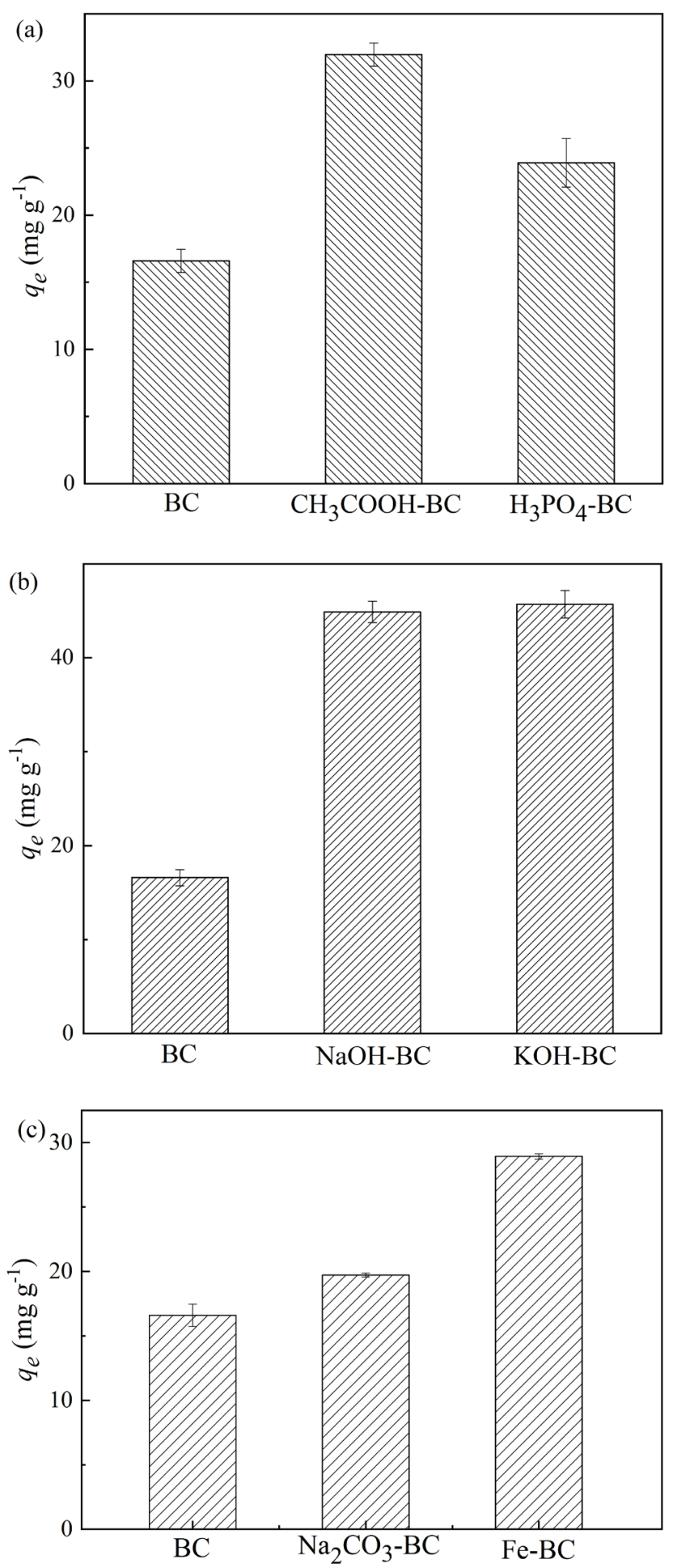

Fig. 7 - Comparison of TC adsorption performance on $B C$ modified by different substances: (a) acid; (b) alkali; (c) salt treatment materials that underwent dehydration under the action of carbonization increased the content of oxygen-containing functional groups. Oxygen-containing functional groups can be directly connected to the benzene ring or aromatic ring of $\mathrm{BC}$, which greatly improves the aromaticity of $\mathrm{BC}$ and its ability to accept $\pi$ electrons. Thus, the $\pi-\pi$ interaction between $\mathrm{BC}$ and organic pollutants was enhanced, which was beneficial to the adsorption of TC by BC. However, some studies have shown that an increase in carboxyl groups $(-\mathrm{COOH})$ will weaken the dispersive force of $\pi-\pi$ action on the surface of $\mathrm{BC}$, thereby weakening the $\pi-\pi$ interaction between $\mathrm{BC}$ and aromatic pollutants. ${ }^{46}$ In addition, oxygen-containing functional groups formed strong hydrogen bonds between $\mathrm{BC}$ and water molecules, causing the formation of a water film and the accumulation of water on the surface of $\mathrm{BC},{ }^{27}$ preventing pollutants from reaching the adsorption site on the surface of the adsorbent, thus reducing the adsorption performance.

\section{Conclusions}

The $\mathrm{TC}$ adsorption capacity of $\mathrm{BC}$ was the best when the carbonization temperature and time of $\mathrm{BC}$ were $700{ }^{\circ} \mathrm{C}$ and $2 \mathrm{~h}$, respectively, and adsorption equilibrium was reached within $24 \mathrm{~h}$. There was little difference in the TC adsorption efficiency of adsorbents prepared by pyrolyzing sludges with different particle sizes. BC contained micropores, mesopores, and macropores, and its surface mainly contained functional groups such as hydroxyl groups $(-\mathrm{OH})$, carbonyl groups $(\mathrm{C}=\mathrm{O})$, and carbon-carbon double bonds $(\mathrm{C}=\mathrm{C})$. The maximum $\mathrm{TC}$ adsorption capacity of $\mathrm{BC}$ reached $20.96 \mathrm{mg} \mathrm{g}^{-1}$ after $24 \mathrm{~h}$ of reaction at $\mathrm{pH}=5.0$ and a low salt ion concentration. The pseudo second-order kinetic model and the Langmuir isothermal model fited the experimental results well, and the internal diffusion and liquid film diffusion controlled the adsorption rate. Compared with $\mathrm{CH}_{3} \mathrm{COOH}, \mathrm{H}_{3} \mathrm{PO}_{4}, \mathrm{Na}_{2} \mathrm{CO}_{3}$, and $\mathrm{FeCl}_{3}$ solutions, the adsorption efficiency of alkaline solution for TC was the highest, reaching $45.90 \mathrm{mg} \mathrm{g}^{-1}$. The TC adsorption process for BC was mainly controlled by static electricity, pore filling, and $\pi-\pi$ interactions. In addition, hydrogen bonding also played a role in TC adsorption by BC.

\section{ACKNOWLEDGMENTS}

This work was supported by The National Key Technology R\&D Program (2018YFD0800105) and leading talent echelon reserve leader funding project of Heilongjiang Province of China. 


\section{References}

1. Conde-Cid, M., Ferreira-Coelho, G., Núñez-Delgado, A., Fernández-Calvio, D., Fernández-Sanjurjo, M. J., Fernández-Sanjurjo, M. J., Competitive adsorption of tetracycline, oxytetracycline and chlortetracycline on soils with different $\mathrm{pH}$ value and organic matter content, Environ. Res 178 (2019) 108669 doi: https://doi.org/10.1016/j.envres.2019.108669

2. Ji, L. L., Chen, W., Duan, L., Zhu, D. Q., Mechanisms for strong adsorption of tetracycline to carbon nanotubes: A comparative study using activated carbon and graphite as adsorbents, Environ. Sci. Technol 43 (2009) 2322. doi: https://doi.org/10.1021/es803268b

3. Wang, L., Chen, Y., Zhao, Y., Du, M. L., Lee, D. J., Toxicity of two tetracycline antibiotics on Stentor coeruleus and Stylonychia lemnae: Potential use as toxicity indicator, Chemosphere 255 (2020) 127011. doi: https://doi.org/10.1016/j.chemosphere.2020.127011

4. Yan, L. L., Wang, C. X., Jiang, J. S., Liu, S., Zheng, Y. Q., Yang, M. Y., Zhang, $Y$., Nitrate removal by alkali-resistant Pseudomonas sp. XS-18 under aerobic conditions: Performance and mechanism, Bioresource Technol. 344 (2022) 126175.

doi: https://doi.org/10.1016/j.biortech.2019.01.033

5. Yu, Z. G., Zhang, C., Zheng, Z. H., Hu, L., Li, X. M., Yang, Z. Z., Ma, C., Zeng, G. M., Enhancing phosphate adsorption capacity of SDS-based magnetite by surface modification of citric acid, Appl. Surf. Sci. 403 (2017) 413. doi: https://doi.org/10.1016/j.apsusc.2017.01.163

6. Zhang, X. N., Lin, X. Y., He, Y., Chen, Y., Luo, X. G., Shang, $R$., Study on adsorption of tetracycline by $\mathrm{Cu}$-immobilized alginate adsorbent from water environment, Int. J. Biol. Macromol. 124 (2019) 418. doi: https://doi.org/10.1016/j.ijbiomac.2018.11.218

7. Yu, J., Xiong, W. P., Li, X., Yang, Z. H., Cao, J., Jia, M. Y., $X u, R$., Zhang, $Y$. R., Functionalized MIL-53(Fe) as efficient adsorbents for removal of tetracycline antibiotics from aqueous solution, Microporous Mesoporous Mat. 290 (2019) 109642 doi: https://doi.org/10.1016/j.ijbiomac.2018.11.218

8. Cheng, D. L., Ngo, H. H., Guo, W. S., Chang, S. W., Nguyen, D. D., Zhang, X. B., Varjani, S., Liu, Y., Feasibility study on a new pomelo peel derived biochar for tetracycline antibiotics removal in swine wastewater, Sci. Total Environ. $\mathbf{7 2 0}$ (2020) 137662.

doi: https://doi.org/10.1016/j.scitotenv.2020.137662

9. Zhang, P. Z., Li, Y. F., Cao, Y. Y., Han, L. J., Characteristics of tetracycline adsorption by cow manure biochar prepared at different pyrolysis temperatures, Bioresource Technol. 285 (2019) 121348.

doi: https://doi.org/10.1016/j.biortech.2019.121348

10. Dai, Y. J., Li, J. J., Shan, D. X., Adsorption of tetracycline in aqueous solution by biochar derived from waste Auricularia auricula dregs, Chemosphere 238 (2020) 124432. doi: https://doi.org/10.1016/j.chemosphere.2019.124432

11. Huang, Y. Q., Wang, Y., Huang, Y. Z., Zhang, L. X., Ye, F., Wang, J. L., Shang, J. G., Liao, Q. J. H., Impact of sediment characteristics on adsorption behavior of typical antibiotics in Lake Taihu, China, Sci. Total Environ. 718 (2020) 137329.

doi: https://doi.org/10.1016/j.scitotenv.2020.137329

12. Nguyen, V. T., Nguyen, T. B., Chen, C. W., Hung, C. M., Vo, T. D. H., Chang, J. H., Dong, C. D., Influence of pyrolysis temperature on polycyclic aromatic hydrocarbons production and tetracycline adsorption behavior of biochar derived from spent coffee ground, Bioresource Technol. 284 (2019) 197. doi: https://doi.org/10.1016/j.biortech.2019.03.096
13. Tang, L., Yu, J. F., Pang, Y., Zeng, G. G., Deng, Y. C., Wang, J. J., Ren, X. Y., Ye, S. J., Peng, B., Feng, H. P., Sustainable efficient adsorbent: Alkali-acid modified magnetic biochar derived from sewage sludge for aqueous organic contaminant removal, Chem. Eng. J. 336 (2018) 160. doi: https://doi.org/10.1016/j.cej.2017.11.048

14. Sun, Y. Y., Li, H., Li, G. C., Gao, B. Y., Yue, Q. Y., Li, X. B., Characterization and ciprofloxacin adsorption properties of activated carbons prepared from biomass wastes by $\mathrm{H}_{3} \mathrm{PO}_{4}$ activation, Bioresource Technol. 217 (2016) 239. doi: https://doi.org/10.1016/j.biortech.2016.03.047

15. Jang, H. M., Yoo, S. H., Choi, Y. K., Park, S. Y., Kan, E. S., Adsorption isotherm, kinetic modeling and mechanism of tetracycline on Pinus taeda-derived activated biochar, Bioresource Technol. 259 (2018) 24. doi: https://doi.org/10.1016/j.biortech.2018.03.013

16. Aghababaei, A., Ncibi, M. C., Sillanpää, M., Optimized removal of oxytetracycline and cadmium from contaminated waters using chemically-activated and pyrolyzed biochars from forest and wood-processing residues, Bioresource Technol. 239 (2017) 28. doi: https://doi.org/10.1016/j.biortech.2017.04.119

17. Zhu, X. D., Liu, Y. C., Qian, F., Zhou, C., Zhang, S. C., Chen, J. M., Preparation of magnetic porous carbon from waste hydrochar by simultaneous activation and magnetization for tetracycline removal, Bioresource Technol. 154 (2014) 209. doi: https://doi.org/10.1016/j.biortech.2013.12.019

18. Cui, L. M., Xu, W. Y., Guo, X. Y., Zhang, Y. K., Wei, Q., Du, $B$., Synthesis of strontium hydroxyapatite embedding ferroferric oxide nano-composite and its application in $\mathrm{Pb}^{2+}$ adsorption, J. Mol. Liq. 197 (2014) 40. doi: https://doi.org/10.1016/j.molliq.2014.04.027

19. Pi, S. S., Li, A., Wei, W., Feng, L., Zhang, G. S., Chen, T., Zhou, X., Sun, H. H., Ma, F., Synthesis of a novel magnetic nano-scale biosorbent using extracellular polymeric substances from Klebsiella $\mathrm{sp}$. J1 for tetracycline adsorption, Bioresource Technol. 245 (2017) 471. doi: https://doi.org/10.1016/j.biortech.2017.08.190

20. Qu, Z., Wu, Y. Q., Zhu, S. Y., Yu, Y., Huo, M. X., Zhang, L. L., Yang, J. K., Bian, D. J., Wang, Y., Green synthesis of magnetic adsorbent using groundwater treatment sludge for tetracycline adsorption, Engineering 5 (2019) 147. doi: https://doi.org/10.1016/j.eng.2019.06.001

21. Chang, Z., Long, G., Zhou, J. L., Ma, C., Valorization of sewage sludge in the fabrication of construction and building materials: A review, Resour. Conserv. Recy. 154 (2020) 104606. doi: https://doi.org/10.1016/j.resconrec.2019.104606

22. Liu, H. D., Xu, G. R., Li, G. B., The characteristics of pharmaceutical sludge-derived biochar and its application for the adsorption of tetracycline, Sci. Total Environ. $\mathbf{7 4 7}$ (2020) 141492. doi: https://doi.org/10.1016/j.scitotenv.2020.141492

23. Li, J., Li, B., Huang, H. M., Zhao, N., Gao, L., Investigation into lanthanum-coated biochar obtained from urban dewatered sewage sludge for enhanced phosphate adsorption, Sci. Total Environ. 714 (2020) 136839. doi: https://doi.org/10.1016/j.scitotenv.2020.136839

24. Tao, S. Y., Liang, S., Chen, Y., Yu, W. B., Huo, H. J., Qiu, J. J., Zhu, Y. W., Xiao, K. K., Hu, J. P., Liu, B. C., Wang, Y. F., Yang, $J . K$., Enhanced sludge dewaterability with sludge-derived biochar activating hydrogen peroxide: Synergism of $\mathrm{Fe}$ and Al elements in biochar, Water Res. 182 (2020) 115927. doi: https://doi.org/10.1016/j.watres.2020.115927 
25. Wei, J., Liu, Y. T., Li, J., Zhu, Y. H., Peng, Y. Z., Adsorption and co-adsorption of tetracycline and doxycycline by onestep synthesized iron loaded sludge biochar, Chemosphere 236 (2019) 124254. doi: https://doi.org/10.1016/j.chemosphere.2019.06.224

26. Zhang, G., Shi, L., Zhang, Y. F., Wei, D., Yan, T., Wei, Q., $D u, B$., Aerobic granular sludge-derived activated carbon: Mineral acid modification and superior dye adsorption capacity, RSC Adv. 5 (2015) 25279. doi: https://doi.org/10.1039/c4ra15216f

27. Yan, L. L., Liu, Y., Wen, Y., Ren, Y., Hao, G. X., Zhang, Y., Role and significance of extracellular polymeric substances from granular sludge for simultaneous removal of organic matter and ammonia nitrogen, Bioresource Technol. 179 (2015) 460.

doi: https://doi.org/10.1016/j.biortech.2014.12.042

28. Wei, D., Ngo, H. H., Guo, W. S., Xu, W. Y., Du, B., Khan, M. $S$., Wei, $Q$., Biosorption performance evaluation of heavy metal onto aerobic granular sludge-derived biochar in the presence of effluent organic matter via batch and fluorescence approaches, Bioresource Technol. 249 (2018) 410. doi: https://doi.org/10.5604/01.3001.0010.5274

29. Yan, L. L., Liu, Y., Zhang, Y., Liu, S., Zhang, Y., $\mathrm{ZnCl}_{2}$ modified biochar derived from aerobic granular sludge for developed microporosity and enhanced adsorption to tetracycline, Bioresource Technol. 297 (2019) 122381. doi: https://doi.org/10.1016/j.biortech.2019.122381

30. Bao, Y. Y., Zhou, Q. X., Wan, Y., Yu, Q., Xie, X. J., Effects of soil/solution ratios and cation types on adsorption and desorption of tetracycline in soils, Soil Sci. Soc. Am. J. 74 (2010) 1553. doi: https://doi.org/10.2136/sssaj2009.0402

31. Jang, H. M., Kan, E. S., Engineered biochar from agricultural waste for removal of tetracycline in water, Bioresource Technol. 284 (2019) 437.

doi: https://doi.org/10.1016/j.biortech.2019.03.131

32. Zhou, Y. Y., Liu, X. C., Xiang, Y. J., Wang, P., Zhang, J. C., Zhang, F. F., Wei, J. H., Luo, L., Lei, M., Tang, L., Modification of biochar derived from sawdust and its application in removal of tetracycline and copper from aqueous solution: Adsorption mechanism and modelling, Bioresource Technol. 245 (2017) 266. doi: https://doi.org/10.1016/j.biortech.2017.08.178

33. Gao, Y., Li, Y., Zhang, L., Huang, H., Hu, J. J., Shah, S. M., $\mathrm{Su}, X$. G., Adsorption and removal of tetracycline antibiotics from aqueous solution by graphene oxide, J. Colloid Interface Sci. 368 (2012) 540. doi: https://doi.org/10.1016/j.jcis.2011.11.015

34. Mutavdžić Pavlović, D., Glavač, A., Gluhak, M., Runje, M., Sorption of albendazole in sediments and soils: Isotherms and kinetics, Chemosphere 193 (2018) 635. doi: https://doi.org/10.1016/j.chemosphere.2017.11.025

35. Ramachandran, P., Vairamuthu, R., Ponnusamy, S., Adsorption isotherms, kinetics, thermodynamics and desorption studies of reactive orange 16 on activated carbon derived from Ananas comosus (L) carbon, ARPN J. Eng. and Appl. Sci. 6 (2011) 15.

36. Yang, X., Xu, G. R., Yu, H. R., Zhang, Z., Preparation of ferric-activated sludge-based adsorbent from biological sludge for tetracycline removal, Bioresource Technol. 211 (2016) 566. doi: https://doi.org/10.1016/j.biortech.2016.03.140

37. Muniandy, L., Adam, F., Mohamed, A. R., Ng, E. P., The synthesis and characterization of high purity mixed microporous/mesoporous activated carbon from rice husk using chemical activation with $\mathrm{NaOH}$ and $\mathrm{KOH}$, Microporous Mesoporous Mat. 197 (2014) 316. doi: https://doi.org/10.1016/j.micromeso.2014.06.020
38. Jing, X. R., Wang, Y. Y., Liu, W. J., Wang, Y. K., Jiang, H., Enhanced adsorption performance of tetracycline in aqueous solutions by methanol-modified biochar, Chem. Eng. J. 248 (2014) 168. doi: https://doi.org/10.1016/j.cej.2014.03.006

39. Zhang, M. C., Li, A. M., Zhou, Q., Shuang, C. D., Zhou, W. $W$., Wang, M. Q., Effect of pore size distribution on tetracycline adsorption using magnetic hypercrosslinked resins, Microporous Mesoporous Mat. 184 (2014) 105. doi: https://doi.org/10.1016/j.micromeso.2013.10.010

40. Liou, T. H., Development of mesoporous structure and high adsorption capacity of biomass-based activated carbon by phosphoric acid and zinc chloride activation, Chem. Eng. J. 158 (2010) 129 doi: https://doi.org/10.1016/j.cej.2009.12.016

41. Rivera-Utrilla, J., Gomez-Pacheco, C. V., Sanchez-Polo, M., Lopez-Penalver, J. J., Ocampo-Perez, R., Tetracycline removal from water by adsorption/bioadsorption on activated carbons and sludge-derived adsorbents, J. Environ. Manage. 131 (2013) 16. doi: https://doi.org/10.1016/j.jenvman.2013.09.024

42. Conde-Cid, M., Ferreira-Coelho, G., Arias-Estévez, M., Fernandez-Calvinho, D., Nunez-Delgado, A., Alvarez-Rodriguez, E., Fernandez-Sanjurjo, M. J., Adsorption/desorption of three tetracycline antibiotics on different soils in binary competitive systems, J. Environ. Manage. 262 (2020) 110337.

doi: https://doi.org/10.1016/j.jenvman.2020.110337

43. Liu, F. B., Zhang, W. T., Chen, W. J., Wang, J., Yang, Q. F., $Z h u$, W. X., Wang, J. L., One-pot synthesis of $\mathrm{NiFe}_{2} \mathrm{O}_{4}$ integrated with EDTA-derived carbon dots for enhanced removal of tetracycline, Chem. Eng. J. 310 (2017) 187. doi: https://doi.org/10.1016/j.cej.2016.10.116

44. Li, H. Q., Hu, J. T., Yao, L. F., Shen, Q., Wang, X. J., Ultrahigh adsorbability towards different antibiotic residues on fore-modified self-functionalized biochar: Competitive adsorption and mechanism studies, J. Hazard. Mater. 390 (2020) 122127. doi: https://doi.org/10.1016/j.jhazmat.2020.122127

45. Kim, J. H., Hyun, S. H., Sorption of ionic and nonionic organic solutes onto giant Miscanthus-derived biochar from methanol-water mixtures, Sci. Total Environ. 615 (2018) 805. doi: https://doi.org/10.1016/j.scitotenv.2017.09.296

46. Nie, T. T., Hao, P. L., Zhao, Z. D., Zhou, W. J., Zhu, L. Z., Effect of oxidation-induced aging on the adsorption and co-adsorption of tetracycline and $\mathrm{Cu}^{2+}$ onto biochar, Sci. Total Environ. 673 (2019) 522. doi: https://doi.org/10.1016/j.scitotenv.2019.04.089

47. Li, H. B., Dong, X. L., da Silva, E. B., de Oliveira, L. M., Chen, Y. S., Ma, L. Q., Mechanisms of metal sorption by biochars: Biochar characteristics and modifications, Chemosphere 178 (2017) 466. doi: https://doi.org/10.1016/j.chemosphere.2017.03.072

48. Chen, T. Y., Luo, L., Deng, S. H., Shi, G. Z., Zhang, S. R., Zhang, Y. Z., Deng, O. P., Wang, L. L., Zhang, J., Wei, L. Y., Sorption of tetracycline on $\mathrm{H}_{3} \mathrm{PO}_{4}$ modified biochar derived from rice straw and swine manure, Bioresource Technol. 267 (2018) 431. doi: https://doi.org/10.1016/j.biortech.2018.07.074

49. Liu, J. L., Zhou, B. Q., Zhang, H., Ma, J., Mu, B., Zhang, W. B., A novel Biochar modified by Chitosan-Fe/S for tetracycline adsorption and studies on site energy distribution, Bioresource Technol. 294 (2019) 122152. doi: https://doi.org/10.1016/j.biortech.2019.122152

50. Peng, L., Ren, Y. Q., Gu, J. D., Qin, P. F., Zeng, Q. R., Shao, J. H., Lei, M., Chai, L. Y., Iron improving bio-char 
derived from microalgae on removal of tetracycline from aqueous system, Environ. Sci. Pollut. Res. 21 (2014) 7631. doi: https://doi.org/10.1007/s11356-014-2677-2

51. Yao, N., Li, C., Yu, J. Y., Xu, Q. Q., Wei, S. Y., Tian, Z. Q., Yang, Z., Yang, W. B., Shen, J., Insight into adsorption of combined antibiotic-heavy metal contaminants on graphene oxide in water, Sep. Purif. Technol. 236 (2020) 116278 doi: https://doi.org/10.1016/j.seppur.2019.116278

52. Zhang, X. B., Zhang, Y. C., Ngo, H. H., Guo, W. S., Qi, L., Characterization and sulfonamide antibiotics adsorption capacity of spent coffee grounds based biochar and hydrochar, Sci. Total Environ. 716 (2020) 137015. doi: https://doi.org/10.1016/j.scitotenv.2020.137015

53. Zhou, Y. Y., He, Y. Z., He, Y. Z., Liu, X. C., Xu, B., Yu, J. F., Dai, C. H., Huang, A. Q., Pang, Y., Luo, L., Analyses of tetracycline adsorption on alkali-acid modified magnetic biochar: Site energy distribution consideration, Sci. Total Environ. 650 (2019) 2260.

doi: https://doi.org/10.1016/j.scitotenv.2018.09.393

54. Zhao, C. Q., Ma, J. G., Li, Z. Y., Xia, H., Liu, H., Yang, Y. $S$., Highly enhanced adsorption performance of tetracycline antibiotics on koh-activated biochar derived from reed plants, RSC Adv. 10 (2020) 5066. doi: https://doi.org/10.1039/C9RA09208K

55. Wang, H., Fang, C. R., Wang, Q., Chu, Y. X., Song, Y. L., Chen, Y. M., Xue, X. D., Sorption of tetracycline on biochar derived from rice straw and swine manure, RSC Adv. 8 (2018) 16260

doi: https://doi.org/10.1039/C8RA01454J
56. Wang, Y. J., Sun, R. J., Xiao, A. Y., Wang, S. Q., Zhou, D. $M$., Phosphate affects the adsorption of tetracycline on two soils with different characteristics, Geoderma 156 (2010) 237.

doi: https://doi.org/10.1016/j.geoderma.2010.02.022

57. Álvarez-Torrellas, S., Rodríguez, A., Ovejero, G., García, $J$., Comparative adsorption performance of ibuprofen and tetracycline from aqueous solution by carbonaceous materials, Chem. Eng. J. 283 (2016) 936. doi: https://doi.org/10.1016/j.cej.2015.08.023

58. Yan, L. L., Chen, W. T., Wang, C. X., Liu, S., Liu, C., Yu, L. B., Zheng, Y. Q., Jiang, J. S., Zhang, Y. L., Xia, C. L., Lam, $S$. $S$., Tetracycline removal in granulation: Influence of extracellular polymers substances, structure, and metabolic function of microbial community, Chemosphere 288 (2022) 132510 .

doi: https://doi.org/10.1016/j.chemosphere.2021.132510

59. Wang, Y., Jiao, W. B., Wang, J. T., Liu, G. F., Gao, H. L., $L \ddot{u}, J$., Amino-functionalized biomass-derived porous carbons with enhanced aqueous adsorption affinity and sensitivity of sulfonamide antibiotics, Bioresource Technol. 277 (2019) 128. doi: https://doi.org/10.1016/j.biortech.2019.01.033

60. An, Q., Miao, Y., Zhao, B., Li, Z., Zhu, S., An alkali modified biochar for enhancing $\mathrm{Mn}^{2+}$ adsorption: Performance and chemical mechanism, Mater. Chem. Phys. 248 (2020) 122895.

doi: https://doi.org/10.1016/j.matchemphys.2020.122895 